\title{
Note
}

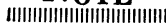

\section{Adsorption Property of Nitrosylruthenium Complex on}

\section{Activated Carbon}

\author{
Takashi Matsumura and Toshio Ishiyama \\ Radiation Center of Osaka Prefecture \\ Received April 20, 1970
}

Decontamination of radioactive ruthenium is one of the most difficult problems involved in the treatment of radioactive waste water, since the behavior of ruthenium solutions towards chemical treatment is extremely complicated. In the present article, the possibility of utilization of the activated carbon has been investigated.

The stock solution and the test liquids were prepared as follows. Ruthenium trichloride containing ${ }^{106} \mathrm{Ru}-{ }^{106} \mathrm{Rh}$ was dissolved in $0.1 \mathrm{~N}$ $\mathrm{HNO}_{3}$ solution. After filtering off silver chloride formed by adding silver nitrate to this solution, sulfuric acid was added to attain $6 N$ in concentration and then sodium bismuthate was added. Ruthenium tetroxide was prepared by distilling the solution at $100^{\circ} \mathrm{C}$ and was collected entirely in cooled $\mathrm{HCl}-$ ethanol mixed solution. After this solution was evaporated to dryness the residue was dissolved in $0.1 \mathrm{~N} \mathrm{HCl}$ solution and dry nitro-

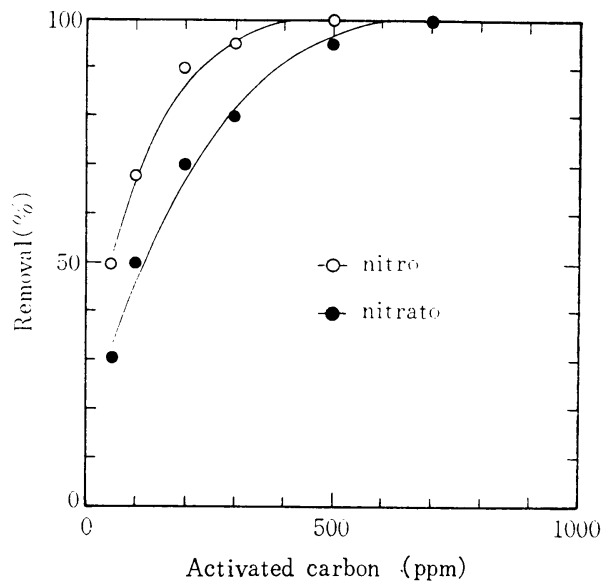

Fig. 1 Effect of the activated carbon concentration on the decontamination. gen oxide was bubbled. Thus nitrosylruthenium chloride solution was prepared. Nitratonitrosyl or nitronitrosylruthenium was synthesized by the addition of fuming nitric acid or sodium nitrite solution to nitrosylruthenium chloride solution, respectively. The radioactive concentration of each stock solution was about $10^{-2} \mu \mathrm{Ci} / \mathrm{ml}$ and the concentration of each
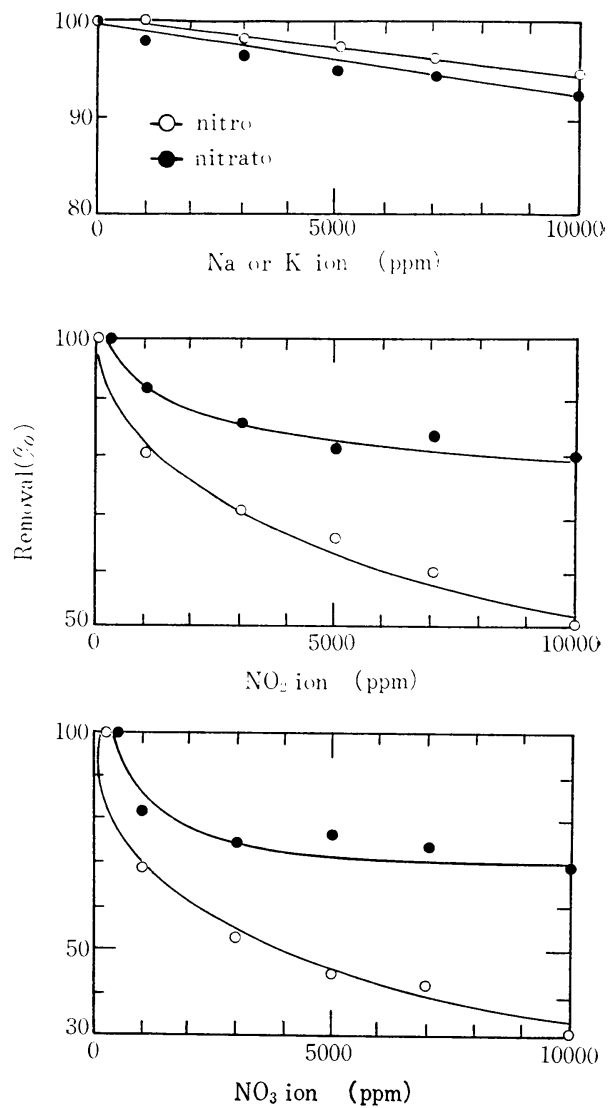

Fig. 2 Effect of competing ion concentration (activated carbon, $1000 \mathrm{ppm}$ ). 
complex was about $10^{-2} N$. The test liquids were prepared by diluting one part of stock solution with 100 parts of distilled water and adjusting $\mathrm{pH}$ at about 7.0.

Adsorption properties were investigated through batch equilibrium method at the room temperature. Commercially available activated carbon which was produced from coconut shell was ground to the standard mesh size lower than 60 . The powdered activated carbon was added to $10 \mathrm{~m} l$ of the test liquid and after being shaken for about $60 \mathrm{~min}$, the suspension was filtered through Toyo Roshi No. 4. Two $\mathrm{m} l$ of filtrate was dried, counted and the removal was calculated. The removals of these complexes increased with the increase of stirring time and reached the steady values after the stirring for about $30 \mathrm{~min}$. Nitronitrosyl or nitratonitrosyl ruthenium complex was entirely removed by the addition of 500 or $700 \mathrm{ppm}$ of the activated carbon, respec- tively, as shown in Fig. 1. However, these complexes were removed neither by ferric hydroxide, phosphate, clay-polyelectrolyte flocculation, nor by the natural ion exchangers. The removals in the case of the test solutions containing foreign matters were measured in the following way. Solution containing $\mathrm{NaCl}$, $\mathrm{KCl}, \mathrm{NaNO}_{2}$ or $\mathrm{NaNO}_{3}$ was used as the test solution. To this solution, $1000 \mathrm{ppm}$ of the activated carbon was added and the removal was measured in the same way described above. The removals were not influenced by the presence of competing $\mathrm{Na}^{+}$or $\mathrm{K}^{+}$ion, however, decreased slightly by the presence of $\mathrm{NO}_{2}^{-}$or $\mathrm{NO}_{3}^{-}$ion, as shown in Fig. 2.

From the experimental results obtained, it is noticed that the activated carbon is an excellent adsorber for the removal of nitrosylruthenium complexes from the radioactive waste water. 